\title{
Recombinant Expression and Purification of Human Cystatin C Biomarker in Escherichia coli for Prediagnostic Renal Disorders
}

\author{
Zahra Abdollah ${ }^{1}$, Samaneh Khodi ${ }^{1}$, Elaheh Gheybi ${ }^{2}$, Jafar Amani ${ }^{i^{*}}$, Ali Karami ${ }^{*}$ \\ ${ }^{1}$ Applied Biotechnology Research Center, Systems Biology and Poisonings Institute, Baqiyatallah University of Medical Sciences, \\ Tehran, Iran \\ ${ }^{2}$ Department of Biology, Faculty of Science, University of Guilan, Rasht, Iran \\ ${ }^{3}$ Applied Microbiology Research Center, Systems Biology and Poisonings Institute, Baqiyatallah University of Medical Sciences, \\ Tehran, Iran \\ ${ }^{4}$ Molecular Biology Research Center, Systems Biology and Poisonings Institute, Baqiyatallah University of Medical Sciences, Tehran, \\ Iran
}

Corresponding Authors: Jafar Amani, PhD, Associate Professor, Applied Microbiology Research Center, Systems Biology and Poisonings Institute, Baqiyatallah University of Medical Sciences, Vanak Sq. Molasadra St. Tehran, Iran. Tel: +98-21-82482592, Fax: +98-21-88068924, Email: jafar.amani@gmail.com

Ali Karami, PhD, Professor, Molecular Biology Research Center, Systems Biology and Poisonings Institute, Baqiyatallah University of Medical Sciences, Mollasadra St. Vanaq Sq. Tehran, Iran. Tel: +98-21-88039883, Fax: +98-21-8057023, Email: alikarami1@yahoo. com

Received November 11, 2017; Revised February 3, 2018; Accepted February 15, 2018; Online Published March 30, 2018

\begin{abstract}
Introduction: Chronic kidney disease is a worldwide health problem and Glomerular filtration rate (GFR) is the most frequently used criteria in the assessment of rental function. Cystatin C as a member of type 2 cystatin superfamily and cysteine-protease inhibitor is found in high concentrations in all biological fluids. This study is aimed to study cystatin $\mathrm{C}$ as a potent biomarker for clinical measurement of renal disorders and other diseases. Materials and Methods: In this study, the human cystatin C construct was analyzed by bioinformatics software. It was cloned and expressed to produce an appropriate antigen for anti-cystatin C (anti-Cys C) obtained from mice Balb/C as a crucial point in the improvement of an enzymelinked immunosorbent assay (ELISA) method. Serum samples were given from 32 hospitalized patients with renal failure and cardiovascular disease and non-hospitalized patients were tested by ELISA method using anti-Cys C obtained from mice Balb/C.

Results: Our findings indicated $0.36-2.4 \mathrm{mg} / \mathrm{L}$ as the best conclusion for antigen cystatin $\mathrm{C}$ in patients' sera and 1/50 dilution for anti-Cys $\mathrm{C}$ obtained from mice Balb/C and showed a relationship between patients with high creatinine and high concentration of cystatin $\mathrm{C}$. In case of five cardiovascular disease patients with normal upper limit of Creatinine we obtained cystatin C lower than kidney failure and raising of cystatin $\mathrm{C}$ in 6 patients with increased TSH were seen.

Conclusions: Polyclonal anti-Cys $\mathrm{C}$ antibodies were obtained through the immunization of Balb/C mice can be employed as an anti-Cys $\mathrm{C}$ in ELISA for diagnosis of some renal dysfunction.

Keywords: Creatinine, Cystatin C, Enzyme-Linked Immunosorbent Assay (ELISA), Glomerular Filtration Rate (GFR)

Citation: Abdollah Z, Khodi S, Gheybi E, Amani J, Karami A. Recombinant expression and purification of human cystatin C Biomarker in Escherichia coli for prediagnostic renal disorders. J Appl Biotechnol Rep. 2018;5(1):13-18. doi:10.29252/jabr.01.01.03.
\end{abstract}

\section{Introduction}

Chronic kidney disease is a worldwide health problem that carries a substantial risk for cardiovascular morbidity and death. Current guidelines define chronic kidney disease as kidney damage or glomerular filtration rate (GFR) less than $60 \mathrm{~mL} / \mathrm{min} / 1.73 \mathrm{~m}^{2}$ for 3 months or more, regardless of cause. GFR is the most frequently used criteria in the assessment of renal function..$^{1-3}$

GFR is measured by using a clearance determined by a biologically inert substance freely filtered through the glomerular membrane and re-entering circulation. Determination of creatinine clearance is the most widely used method for non-invasive estimation of GFR. However, creatinine evaluation is influenced by muscle mass, body surface and food intake; therefore, one must consider age, sex, height, and body composition when evaluating patient sample. Creatinine clearance leads to significant over estimation on GFR in those patients with highly decreased GFR due to tubular secretion. The collection of 24-hour urine is time consuming and creates additional sources of errors. ${ }^{3,4}$

But cystatin $\mathrm{C}$ produced at a constant rate and the production rate in humans is remarkably constant over the entire lifetime. Elimination from the circulation is almost entirely via glomerular filtration. For this reason the serum 
concentration of cystatin $\mathrm{C}$ is independent from muscle mass, sex and diet. ${ }^{4}$ Therefore, cystatin $\mathrm{C}$ in plasma and serum has been proposed as a more sensitive marker for GFR in children and adults, and several studies have suggested that cystatin $\mathrm{C}$ is superior to serum creatinine for estimation of GFR. Patient groups which benefit most are those with mild to moderate kidney disease and also those in acute renal failure, where toxic drugs have to be administered which are excrete by glomerular filtration, especially elder people, children, pregnant woman with suspicion of preeclampsia, diabetics, people with diseases of skeletal muscle and renal transplant recipients. ${ }^{1,5}$

Cystatin $C$ is a member of type 2 cystatin superfamily $y^{6,7}$ and a basic proteinase inhibitor with a low molecular weight of $13 \mathrm{kDa}$ that produced by all human nucleated cells ${ }^{8}$ and is found in high concentrations in biological fluids. ${ }^{9,10}$ Cystatin $\mathrm{C}$ is freely filtrated by the glomerulus and is not selected by the tubular cells and is reabsorbed by the tubular epithelial cells and is subsequently catabolized. Therefore, the serum cystatin $\mathrm{C}$ concentration may be considered as an endogenous marker of the GFR. ${ }^{6,11}$ Meanwhile, the use of cystatin $\mathrm{C}$ is interfered by non-renal factors such as glucocorticoid therapy, malignancy or thyroid disorders, which influence serum cystatin C concentrations. ${ }^{12}$ Cyctatins are a superfamily of cystatin proteinases found in both plants and animals. ${ }^{13}$ They comprise a group of proteinase inhibitors, widely distributed in tissues and body fluids and from tight complexes with cysteine proteases such as cathepsin $\mathrm{H}, \mathrm{L}$, and S. ${ }^{10}$ Cystatin $\mathrm{C}$ is thought to serve an important physiological role as a local regulator of this enzymatic activity. Cystatin $\mathrm{C}$ is increased in patients with malignant disease and is related to the insufficiency of renal function and appears to be a better marker than creatinine. ${ }^{14}$ The blood concentration of cystatin C depends on the GFR. ${ }^{15}$ On the other hand, low levels of cystatin $\mathrm{C}$ involves causing the breakdown of the elastic laminae and subsequently, the atherosclerosis and abdominal aortic aneurysm. ${ }^{16}$ Changes in cystatin $\mathrm{C}$ have been demonstrated in a number of cardiovascular diseases, including atherosclerosis, amyotrophic lateral sclerosis (ALS) and myocardial infarction. ${ }^{10,17}$ Plasma cystatin $\mathrm{C}$ has also been reported to be a useful tool in the detection of incipient nephropathy in patients with non-insulin dependent diabetes mellitus. ${ }^{18}$ Thus thyroid function has a major impact on cystatin C levels. ${ }^{19}$ Concentration of cystatin $\mathrm{C}$ is interfered by non-renal factors, such as glucocorticoid therapy, malignancy, cyclosporins, hyperhomocysteinemia, liver disease, heart failure. ${ }^{12,20}$ The aim of this study was to examine the application of mouse polyAb against cystatin $C$ protein patient serum in indirect enzyme-linked immunosorbent assay (ELISA) that by recombinant antigen cystatin $\mathrm{C}$ in Balb/C mice has been produced. As screened cystatin $\mathrm{C}$ antigen in positive cases by a mouse polyAb against for diagnosis of some of disorders especially renal dysfunction.

\section{Materials and Methods}

Specimens

A total of 68 serum from 36 healthy and 32 patients were obtained hospitalized with renal failure and cardiovascular disease and non-hospitalized patients from Modares hospital, Tehran, Iran. Serum samples were collected and stored at $-70^{\circ} \mathrm{C}$ until analyzed.

\section{Construct Design}

Related sequences, human cystatin C molecule consists of a single polypeptide chain of 120 amino acids with molecular mass of $13 \mathrm{kDa}$ and is a non-glycosylated, basic protein which has 2 disulfide bridges located near the carboxyl terminus. ${ }^{21}$ The protein contains an extra His-tag at N-terminus. The sequence obtained through other bioinformatics methods were studied and the second and third structure of mRNA and protein produced by it were investigated. ${ }^{22}$ Optimized sequence after evaluation was ordered for synthesis.

Preparation and Confirmation of Recombinant CysC Protein The CysC gene (GenBank accession no NM_000099) was optimized according to codon usage bases of Escherichia coli and synthesized in pUC57 vector (Biomatik). Synthesized sequence was BamHI and HindIII digested and inserted into similarly digested pET-28a (+) using T4 ligase (Fermentas, Germany) to generate pET-28a (+)-CysC plasmid. After each digestion the fragments were purified with GeneJET ${ }^{\mathrm{TM}} \mathrm{Gel}$ Extraction Kit (Fermentas, \# K0691). Plasmid isolation was carried out using GeneJE ${ }^{\mathrm{TM}}$ Plasmid Miniprep Kit (Fermentas, \# K0502) as per the manufacturer's protocol. E. coli BL21 (DE3) was used as a host cell transformed by micro-pulser (Bio-Rad) at 1200 and in a $0.1 \mathrm{~cm}$ electroporation cuvette. Preparation of electrocompetent cells and electroporation were carried out as described in Bio-Rad's MicroPulser Electroporation Apparatus Operating Instructions and Applications Guide (Bio-Rad, \#165-2100). ${ }^{23}$ The cells were plated onto LB plates containing $40 \mu \mathrm{g} / \mu \mathrm{L}$ kanamycine to obtain positively transformed colonies. Transformants were confirmed using polymerase chain reaction (PCR) technique by T7-promter-primer and T7-Terminal-primer for pET28a (+), and double-digestion by restriction enzymes. Amplification was made in a total volume of $25 \mu \mathrm{L}$ of reaction mixture containing $0.3 \mu \mathrm{L}$ of genomic $\mathrm{DNA}(0.5 \mu \mathrm{g} / \mu \mathrm{L}), 2$ $\mu \mathrm{L}$ of $10 \times$ Taq polymerase buffer, $0.8 \mu \mathrm{L} \mathrm{MgCl}_{2}(25 \mathrm{mM})$, $0.4 \mu \mathrm{L}$ dNTP Mix (10 mM each), $0.4 \mu \mathrm{L}$ of each primer $(25$ pmol) and $1 \mu \mathrm{L}$ Taq polymerase PCR mix. A total of 30 cycles was performed with the first denaturation at $95^{\circ} \mathrm{C}$ for 15 seconds, then 30 cycles at $94^{\circ} \mathrm{C}$ for 50 seconds, $59^{\circ} \mathrm{C}$ for 50 seconds and $72^{\circ} \mathrm{C}$ for 1 minute, and the final extension at $72^{\circ} \mathrm{C}$ for 3 minutes. The amplified products were analyzed by electrophoresis with a $1 \%$ agarose gel containing SYBR green and UV-transilluminator visualization.

Cells harboring recombinant plasmids were induced with $1 \mathrm{mM}$ isopropyl-D-thiogalactopyranoside (IPTG) when cells were grown to an $\mathrm{OD}_{600}=0.6$ and cultured at $37^{\circ} \mathrm{C}$ for 5 hours and SDS-PAGE 15\% was applied to verify Cys C expression.

\section{Cys C Purification Using Nickel Affinity Column}

Induced colony harboring pET-28a (+)-CysC plasmid was used for protein purification. The bacterial samples were given off before and after the induction and analyzed by using sodium dodecyle-sulfate-poly acrylamide gel electrophoresis 
(SDS-PAGE). The cells were harvested by centrifugation (5000 rpm for 10 minutes at $4^{\circ} \mathrm{C}$ ), and the resultant pellet was resuspended in $5 \mathrm{ml}$ equilibration buffer $(0.4$ urea, $50 \mathrm{mM}$ tris and $0.5 \mathrm{M} \mathrm{NaCl})$ and sonicated $(5 \times 10 \mathrm{~s})$ on ice. The resultant cell lysate was centrifuged at $14000 \mathrm{rpm}$ for 5 minutes at $4^{\circ} \mathrm{C}$, suspended in $5 \mathrm{~mL}$ equilibration buffer, and then incubated over night at $4^{\circ} \mathrm{C}$. It was centrifuged again the next day at $14000 \mathrm{rpm}$ for 5 minutes at $4^{\circ} \mathrm{C}$. The clear supernatant was collected and used for protein purification. The protein was purified under denaturing condition according to the immobilized metal affinity chromatography (IMAC) column using Ni-NTA agarose (Qiagen) based on its N-terminal 6 His Tag. ${ }^{24}$ The prepared column was washed with double distilled water then with $1.5 \mathrm{~mL}$ Mes buffer $(20 \mathrm{mM})$. After complete emission of Mes buffer, $2 \mathrm{~mL}$ cell lysate was applied to the column at a flow rate of $15 \mathrm{drops} / \mathrm{min}$ and allowed to bind followed by $2 \mathrm{~mL}$ washing buffer. The bound protein was eluted with elution buffer ( $4 \mathrm{mM}$ urea, $50 \mathrm{mM}$ Tris $0.5 \mathrm{M} \mathrm{NaCl}$ and $1 \mathrm{mM}$ imidazole). Finally $500 \mu \mathrm{L}$ Mes buffer $(20 \mathrm{mM})$ was used. SDS-PAGE 15\% and Western blotting analysis were applied to verify cystatin C expression. SDS-PAGE 15\% and Western blotting analysis were applied to verify cystatin $\mathrm{C}$ expression, meanwhile the concentration was measured using by chemiluminescence and turbidometry.

\section{Western Blot Analysis}

For Western blotting, proteins in the culture supernatants were subjected to SDS-PAGE using a $15 \%$ polyacrylamide and electroblotted to a polyvinylidene difluoride (PVDF) membrane using transfer buffer (39 mM glycine, $48 \mathrm{mM}$ Tris-base, $0.037 \%$ SDS, and 20\% methanol) by Bio-Rad Mini Protean II System. The membrane was blocked by 3\% BSA for 1 hour at $37^{\circ} \mathrm{C}$. Then incubated in a 1:1000 dilution of mice anti-His-tag IgG (Roche) in the PBST (PBS contain $0.05 \%$ Tween 20 ), with gentle shaking for 1 hour at $37^{\circ} \mathrm{C}$. Followed by washing with PBST three times and incubation in 1:2000 dilution of HRP-conjugated goat anti-mouse IgG antibody (SIGMA), with gentle shaking for 1 hour at $37^{\circ} \mathrm{C}$. The membrane was washed three times with PBST and detected by colorimetry with diamino benzoic acid (DAB) and hydrogen peroxide $\left(\mathrm{H}_{2} \mathrm{O}_{2}\right)$. Chromogenic reaction was stopped by rinsing the membrane twice with distilled water. ${ }^{25}$

\section{Mouse Immunization and Evaluation of Anti-Cys C Sera}

Ten micrograms recombinant CysC protein was injected subcutaneously into 5-week-old female Balb/C mice (from Pasteur Institute of Iran) with complete Freund's adjuvant (SIGMA). Incomplete Freund's adjuvant was used for subsequent injections on day 14 and 28, as the booster doses. As a negative control, complete and incomplete Freund's adjuvant was injected with the same procedure. The mice serum was collected after checking the antibody against CysC protein by indirect ELISA and stored at $-70^{\circ} \mathrm{C}$ until use. ${ }^{26}$

\section{Enzyme-Linked Immunosorbent Assay Analysis}

Enzyme-linked immunosorbent assay analysis (ELISA) was used to determine the antibody specific responses. Microplates were coated with $5 \mu \mathrm{g} / \mathrm{mL}$ of recombinant antigen and used standard kit Cystatin C (NSO, M1-A146) for evaluation of recombinant antigen. After that based on serial dilution of recombinant antigen was drawn the standard curve (in 100 $\mu \mathrm{L}$ volume) diluted in $0.1 \mathrm{M}$ carbonated/biocarbonate buffer ( $\mathrm{pH}$ 9.6) was coated onto the bottom of 96-well plate for 2 hours at $37^{\circ} \mathrm{C}$ after 3 washes, the microplates were coated with a blocking solution ( $1 \%$ bovine serum, albumin, $300 \mu \mathrm{L}$ ) diluted with phosphate-buffered saline (PBS) for 45 minutes at room temperature. After 3 washes with PBST, antibodies obtained from mouse Balb/C were coated, diluted (1:50) in PBS containing $0.1 \%$ tween 20 and vibrated for 2 hours at room temperature. They were then coated with anti-mouse IgG conjugated with peroxidase conjugate at a dilution of 1:5000 as the second antibody for 1 hour on the vibrator in the dark. Adding OPD as a peroxidase substrate, and then the reaction was stopped by $100 \mu \mathrm{L}$ of TMB solution for the readout at $450 \mathrm{~nm}$ to visualize the antigen-antibody reaction ELISA test to quantify Cystatin C in patients' sera was performed as described above.

\section{ELISA Test to Quantify Cystatin C in Patients' Sera}

Microplates were coated with $5 \mu \mathrm{g}$ human sera Cys C protein from 32 hospitalized patients with renal failure and cardiovascular disease and non-hospitalized patients referred to Modares hospital, followed by incubation for overnight at $4^{\circ} \mathrm{C}$. The reaction wells were blocked with $3 \%$ BSA solution for 45 minutes at $37^{\circ} \mathrm{C}$. Plates were washed with PBST for three times, and then treated with anti-human Cys $\mathrm{C}$ obtained from mouse Balb/C that was diluted to $1: 50$ in coating buffer $\left(\mathrm{pH}\right.$ 9.6) and incubated for 60 minutes at $37^{\circ} \mathrm{C}$, then $1 / 5000$ diluted anti-mouse IgG conjugated with peroxidase as the second antibody was added followed by incubation for 1 hour at $37^{\circ} \mathrm{C}$. Color was appeared after adding OPD as a peroxidase substrate, and then the reaction was stopped by $100 \mu \mathrm{L}$ of TMB solution for the readout at $450 \mathrm{~nm}$. To calculate the relative amount of Cys $\mathrm{C}$ protein in the serum samples, a standard curve was obtained using the optical density of ELISA. Then the optical density of Cys C protein in patients' serum tested by ELISA procedure was estimated based on the standard curve.

The mean \pm 2 SD of the absorbance reading of the 36 healthy individuals at $0.47 \%$ was considered as the cutoff for positive reactions. The ELISA was also performed in different concentrations of Cys $\mathrm{C}$ protein with constant dilution of anti-Cys $\mathrm{C}$ and vice versa to plot a standard curve.

\section{Statistical Analysis}

All Statistical analysis was performed using SPSS software (version 16.0; SPSS, Inc.) and data analysis software (Microsoft Excel 2007). $P$ value of $<0.05$ was considered as statistically significant.

\section{Ethical Considerations}

All procedures performed in studies involving human participants were in accordance with the ethical standards of the institutional and national research committee and with the 1964 Helsinki declaration and its later amendments. 


\section{Results}

To develop an ELISA test to detect Cys c antigens in human sera, an antigenic sequence CysC was constructed (120 amino acids). The bioinformatics results showed that the construct was stable and immunogenic domain was exposed (data not shown).

The fragments digested from pUC57-CysC were cloned into digested pET-28a $(+)$ vectors. Released fragment from pET-28a (+)-CysC with $2 \mathrm{BamHI}$ and HindIII restriction enzymes (Figure 1A) and the $360 \mathrm{bp}$ of the $C y s C$ gene isolated through PCR (Figure 1B) indicate the successful cloning of the CysC gene. The $13 \mathrm{kDa}$ CysC protein detected in expressed protein (Figure 2) and purified by chromatography using Ni-NTA agarose (Qiagen) (Figure 3) and confirmed by appearing a proper band by Western blotting (Figure 4). Protein concentration measured by chemiluminescence and turbidimetry was 5.01 and $8 \mu \mathrm{g} / \mathrm{mL}$, respectively. Mice were immunized with recombinant $\mathrm{Cyc} \mathrm{C}$ protein complete and incomplete Freund's adjuvants three times within 6 weeks. The sera were collected after immunization and assessed for Cys C specific IgG by ELISA method (Figure 4). Non-immunized mice sera were used as control $(P<0.05) .1 / 50$ dilution resulted

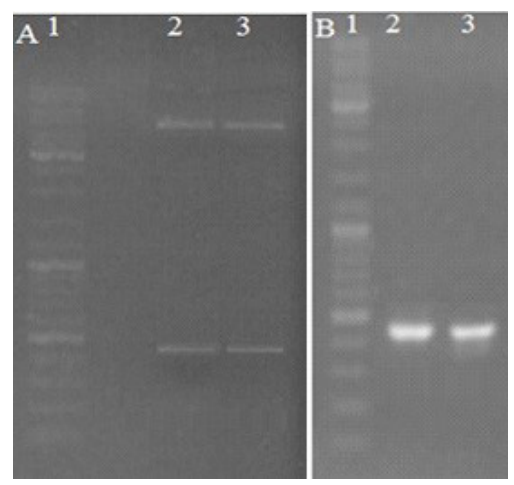

Figure 1. A) lane 1, Gene ruler. Lane 2, 3, Released cys $C$ fragment from pET-28a (+)-CysC plasmid using BamHI and HindIII. B) Lane 1, Gene ruler sm0333. Lane 2, 3, PCR products from pET-28a (+)-CysC plasmid. Lane 4, Negative control.

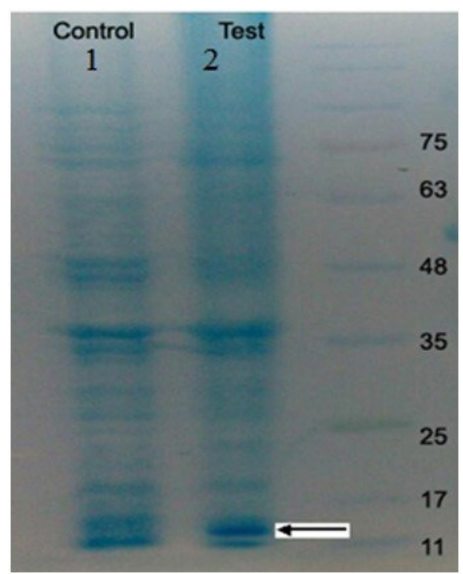

Figure 2. Detection of Protein Expressed by pET-28a (+)-Cys C Using 15\% SDS-PAGE. A) Lane 1: Cell lacking pET-28a (+)-Cys C, Lane 2: Cell harboring $\mathrm{pET}-28 \mathrm{a}(+)-C y s C$, Protein size marker. in the optimum density. A standard plot curve from serial dilution of Cys $\mathrm{C}$ was obtained, which indicates a relationship between optical density and cystatin $\mathrm{C}$ recombinant protein to estimate the Cys $\mathrm{C}$ protein in patient's sera (Figure 5). The optimum dilution of anti-Cys C (1:50) was used to calculate the concentration of Cys $\mathrm{C}$ for 32 patients led to a maximum optical density in patients with acute and chronic renal failure and the minimum amount in patients (Figure 6). ELISA were estimated based on comparing their optical densities with the standard curve with sample test to calculate the relative amount of Cys $\mathrm{C}$ antigen present in the serum patients. The cutoff values of $0.36-2.4 \mu \mathrm{g} / \mathrm{mL}$ were considered levels of pretreatment for Cys C antigens, respectively, sensitivity (95\%), and specificity (98\%) were determined by SPSS analysis.

\section{Discussion}

Cystatin C or cystatin 3 is a protein encoded by the CST3 gene, was originally described as a constituent of normal cerebrospinal fluid (CSF) and of urine from patients with renal failure. In humans, all cells with nucleus produce cystatin $\mathrm{C}$ as a chain of 120 amino acids. It is found in virtually all tissues and bodily fluids. Cystatin C, which belongs to the type II cystatin gene family, is a potent inhibitor of lysosomal proteinases and probably one of the most important extracellular inhibitor of cysteine proteases. ${ }^{27,28}$

Cystatin C is freely filtered through the glomerulus, is not secreted by the tubule or eliminated via any extra renal route, and is almost completely absorbed and metabolized by proximal tubular cells. Therefore, the plasma concentration of cystatin $\mathrm{C}$ is almost exclusively determined by the GFR, making cystatin $\mathrm{C}$ an excellent indicator of GFR. Cystatin $\mathrm{C}$ has advantages over routine clinical measures of renal function. It is more accurate than plasma creatinine and the Cockcroft-Gault estimation of creatinine clearance and is more reliable than the 24 hours creatinine clearance. There is a growing body of evidence that suggests that cystatin $\mathrm{C}$ can be used to detect kidney disease at earlier stages than serum creatinine which may help facilitate prevention efforts in the elderly and those with diabetes, hypertension,

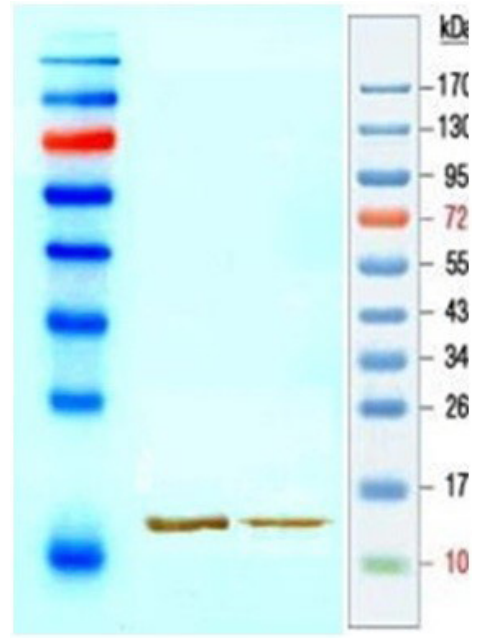

Figure 3. Western Blotting Analysis of Purified Recombinant Protein CysC Using Histidine Antibody, Protein Size Marker.. 


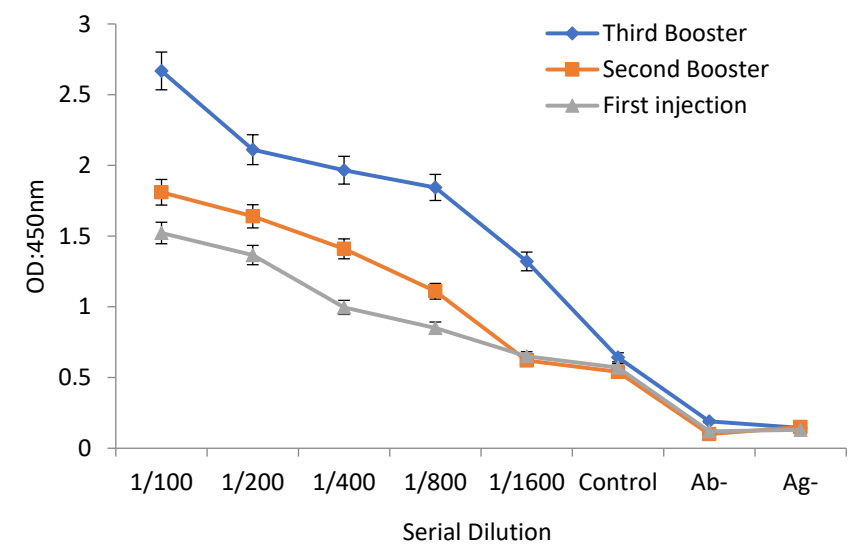

Figure 4. Optical Density Based on Serial Dilution of Anti-Cys C obtained From Mice BALB/C.

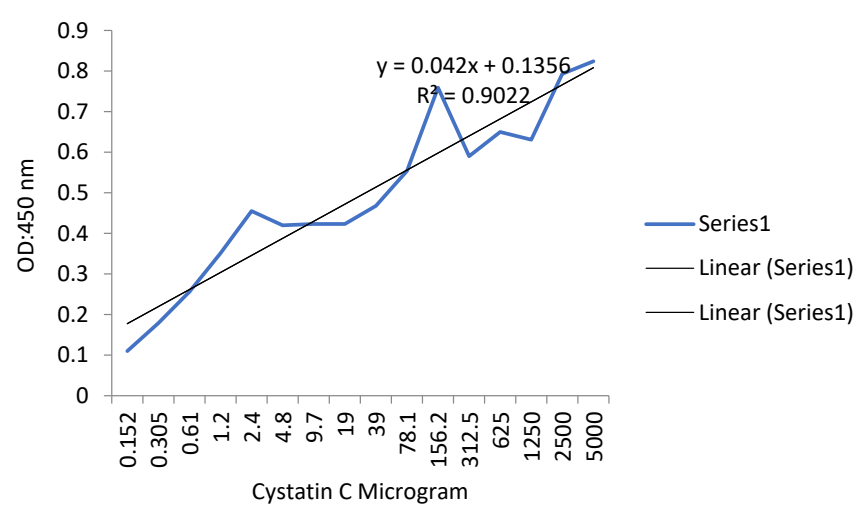

Figure 5. A Standard Plot Curve From Serial Dilution of Cys C.

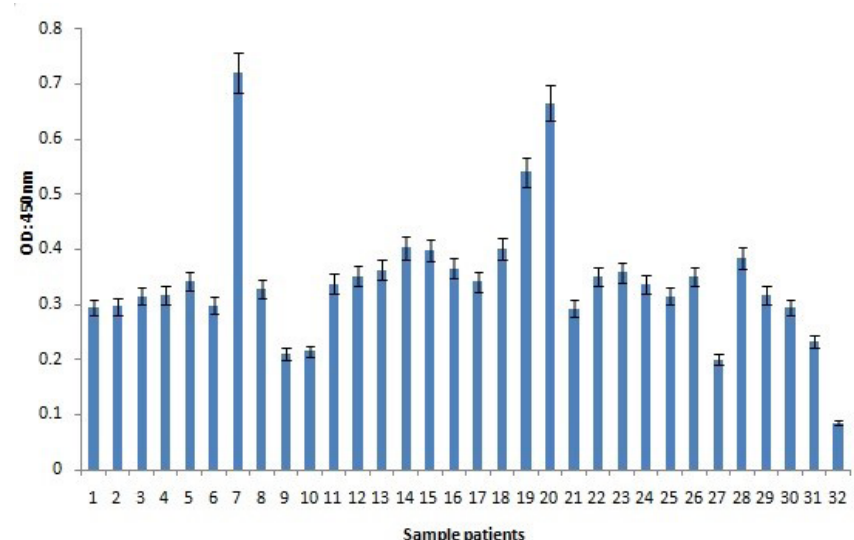

Figure 6. Quantifying ELISA for Calculating Cys C Protein in the Patients' Sera.

or cardiovascular, as well as its relation to disease involving amyloid such as Alzheimer. ${ }^{3,27}$

Moreover, cystatin C is involved in network reorganization in the epileptic dentate gyrus. The standard method used in this ELISA is recombinant human cystatin C, consisting of 120 amino acids with the molecular mass nearly $13 \mathrm{kDa}$. Rapid determination of renal function followed by timely therapy could improve patient care. Human cystatin C seems to be an excellent marker of renal function, available evidence demonstrated that serum cystatin $\mathrm{C}$ is superior to serum creatinine as a marker of GFR, particularly in identifying initial small decreases in GFR. In contrast to serum creatinine, serum cystatin $\mathrm{C}$ in unaffected by muscle mass, age, gender or race and it is not affected by most drugs, infections, diet or inflammation. ${ }^{29,30}$ Cystatin $\mathrm{C}$ has been associated with hyperhomocysteinemia, which is found in renal transplant patients and it has been shown to increase with the progression of liver disease. ${ }^{31}$ The human cystatin family comprises 11 identified proteins. Two of these, cystatin A and B form the family 1 cystatins and are mainly intracellular proteins, but cystatins C, D, E, F, S, SA and SN are mainly extracellular or transcellular proteins and constitute the family 2 cystatins (http://www.slideshare.net/ksodhi21/cystatin-c-2014). The family 3 cystatins, high and low molecular weight kininogen, contain three cystatin domains and mainly intravascular proteins, which in addition to being inhibitors of cysteine proteases also ate involved in the coagulation process and in the production of vasoactive peptides. ${ }^{32}$

In this study, His-tagged human cystatin $C$ was expressed in E. coli BL21 (DE3). After 3 hours induction with $1 \mathrm{mM}$ IPTG at $37^{\circ} \mathrm{C}$, the cells harvested and subjected to ultrasonic treatment. The sonicated extract was separated into soluble and insoluble fractions by centrifugation at $14000 \mathrm{rpm}$ for $30 \mathrm{~min}$ at $4^{\circ} \mathrm{C}$. Expressed proteins in E. coli were analyzed by SDS-PAGE $15 \%$ and coomassie brilliant blue staining. SDSPAGE analysis result is shown in Figure 1. The presence of a predominant induction band with molecular weight around $15 \mathrm{kDa}$ (between 10-17 $\mathrm{kDa}$ ) after purifying the fusion protein human cystatin $\mathrm{C}$ with affinity chromatography, each fraction was collected manually, and the fractions were analyzed by SDS-PAGE and western blotting procedures (Figures 2, 3 and 4). In our study, a relatively high amount of the cystatin $\mathrm{C}$ fusion protein was obtained in the soluble form, while some amount of the fusion protein was also found in the inclusion body. In this study mice Balb/C were injected with recombinant protein cystatin $\mathrm{C}$ using complete and incomplete Freund's adjutants three times within 6 weeks and then sera were collected to asses specific antibodies after immunization and detect protein cystatin $\mathrm{C}$ in patients with chronic kidney disease (CKD) and some of disease. To set up a reliable ELISA method and determine sensitivity and specificity of ELISA, One ELISA was designated for qualifying human cystatin $\mathrm{C}$ antigen in patient's sera. Recombinant protein with coating buffer was prepared as serial dilution (1:2 to $1: 64)$ and the best response for ELISA obtained at dilution of 1:4 for antigen. Consequently to optimize the best dilution of anti-cystatin C were diluted (1:5 to 1:100) while concentration of antigen was remained constant and resulted in the best conclusion at dilution of 1:50 for anti-cystatin C. After coating $5 \mu \mathrm{g}$ recombinant protein and preparation of serial dilution for antigen we obtained a curve based on optical densities against concentration of cystatin $\mathrm{C}$ which it can used to estimate cystatin $\mathrm{C}$ values in patients sera.

\section{Conclusions}

Our findings indicated a relationship between patients with high creatinine (19 patients) and high concentration of 
Cystatin C. In case of five cardiovascular disease patients with normal upper limit of creatinine we obtained cystatin $\mathrm{C}$ lower than kidney failure and raising of cystatin $\mathrm{C}$ in 6 patient with increased thyroid-stimulating hormone (TSH) were seen. Consequently, polyclonal anti-Cys $\mathrm{C}$ antibodies were obtained through the immunization of Balb/C mice with human recombinant cystatin $C$ expressed in $E$. coli can be employed as an anti-Cys $\mathrm{C}$ in ELISA for diagnosis of some of disorders especially renal dysfunction.

\section{Authors' Contributions}

All authors contributed equally to this research.

\section{Conflict of Interest Disclosures}

The authors declare they have no conflicts of interest.

\section{Acknowledgments}

The authors thank from colleagues in Applied Biotechnology Research Center, Systems Biology and Poisonings Institute, Baqiyatallah University of Medical Science, for their helpful discussions.

\section{References}

1. Levey AS, Coresh J, Balk E, et al. National Kidney Foundation practice guidelines for chronic kidney disease: evaluation, classification, and stratification. Ann Intern Med. 2003;139(2):137147.

2. Myers GL, Miller WG, Coresh J, et al. Recommendations for improving serum creatinine measurement: a report from the Laboratory Working Group of the National Kidney Disease Education Program. Clin Chem. 2006;52(1):5-18. doi:10.1373/ clinchem.2005.0525144

3. Rule AD, Larson TS, Bergstralh EJ, Slezak JM, Jacobsen SJ, Cosio FG. Using serum creatinine to estimate glomerular filtration rate: accuracy in good health and in chronic kidney disease. Ann Intern Med. 2004;141(12):929-937.

4. Inker LA, Schmid $\mathrm{CH}$, Tighiouart $\mathrm{H}$, et al. Estimating glomerular filtration rate from serum creatinine and cystatin C. N Engl J Med. 2012;367(1):20-29. doi:10.1056/NEJMoa1114248

5. Jung K, Jung M. Cystatin C: a promising marker of glomerular filtration rate to replace creatinine. Nephron. 1995;70(3):370-371. doi:10.1159/000188621

6. Zhang Z, Lu B, Sheng X, Jin N. Cystatin C in prediction of acute kidney injury: a systemic review and meta-analysis. Am J Kidney Dis. 2011;58(3):356-365. doi:10.1053/j.ajkd.2011.02.389

7. Mousa M, El-Saeid M, Hamdy M. Evaluation of Cystatin C, Fibronectin and Alpha-Feto Protein as Biochemical Markers in Patients with Liver Diseases. J Am Sci. 2012;8(7):770-779.

8. Bengtsson E, To F, Hakansson K, et al. Lack of the cysteine protease inhibitor cystatin $\mathrm{C}$ promotes atherosclerosis in apolipoprotein E-deficient mice. Arterioscler Thromb Vasc Biol. 2005;25(10):21512156. doi:10.1161/01.ATV.0000179600.34086.7d

9. Gashenko EA, Lebedeva VA, Brak IV, Tsykalenko EA, Vinokurova GV, Korolenko TA. Evaluation of serum procathepsin B, cystatin $\mathrm{B}$ and cystatin $\mathrm{C}$ as possible biomarkers of ovarian cancer. Int J Circumpolar Health. 2013;72. doi:10.3402/ijch.v72i0.21215

10. Wilson ME, Boumaza I, Bowser R. Measurement of cystatin C functional activity in the cerebrospinal fluid of amyotrophic lateral sclerosis and control subjects. Fluids Barriers CNS. 2013;10(1):15. doi:10.1186/2045-8118-10-15

11. Andersen TB, Jodal $L$, Boegsted $M$, et al. GFR prediction from cystatin $\mathrm{C}$ and creatinine in children: effect of including body cell mass. Am J Kidney Dis. 2012;59(1):50-57. doi:10.1053/j. ajkd.2011.09.013

12. Brguljan PM, Cimerman N. Human cystatin C. Turk J Biochem. 2007;32(3):95-103.

13. Turk B, Turk D, Salvesen GS. Regulating cysteine protease activity: essential role of protease inhibitors as guardians and regulators. Curr Pharm Des. 2002;8(18):1623-1637.
14. Dousdampanis P, Trigka K, Fourtounas C. Diagnosis and management of chronic kidney disease in the elderly: a field of ongoing debate. Aging Dis. 2012;3(5):360-372.

15. Hayashi $M$, Iwamoto $S$, Sato $S$, et al. Efficient production of recombinant cystatin $\mathrm{C}$ using a peptide-tag, $4 \mathrm{AaCter}$, that facilitates formation of insoluble protein inclusion bodies in Escherichia coli. Protein Expr Purif. 2013;88(2):230-234. doi:10.1016/j. pep.2013.01.011

16. Shi GP, Sukhova GK, Grubb A, et al. Cystatin C deficiency in human atherosclerosis and aortic aneurysms. J Clin Invest. 1999;104(9):1191-1197. doi:10.1172/jci7709

17. Chen ZK, Ge CJ, Hu SJ. [The relationship of cystatin C and cardiovascular diseases]. Sheng Li Ke Xue Jin Zhan. 2003;34(3):269-271.

18. Piwowar A, Knapik-Kordecka M, Buczynska H, Warwas M. Plasma cystatin $\mathrm{C}$ concentration in non-insulin-dependent diabetes mellitus: relation with nephropathy. Arch Immunol Ther Exp (Warsz). 1999;47(5):327-331.

19. Wang F, Pan W, Wang H, Zhou Y, Wang S, Pan S. The impacts of thyroid function on the diagnostic accuracy of cystatin $\mathrm{C}$ to detect acute kidney injury in ICU patients: a prospective, observational study. Crit Care. 2014;18(1):R9. doi:10.1186/cc13186

20. Chew JS, Saleem M, Florkowski CM, George PM. Cystatin C--a paradigm of evidence based laboratory medicine. Clin Biochem Rev. 2008;29(2):47-62.

21. Ristiniemi N. Quantification and Clinical Relevance of Cystatin C. Turku, Finland: Annales Universitatis Turkuensis; 2014.

22. Abdollah Z, Karami A, Amani J, Khodi S, Gheybi E. In silico study of Cystatin C protein to Develop an ELISA kit using Computational tools and servers. Bull Environ Pharmacol Life Sci. 2015;4(7):8794.

23. Heiat M, Aghamollaei H, Hoseini SM, Abbasi Larki R, Yari K. Optimization of plasmid electrotransformation into Escherichia coli using Taguchi statistical method. Afr J Biotechnol. 2012;11(30):7603-7608. doi:10.5897/ajb11.4078

24. Amani J, Salmanian AH, Rafati S, Mousavi SL. Immunogenic properties of chimeric protein from espA, eae and tir genes of Escherichia coli O157:H7. Vaccine. 2010;28(42):6923-6929. doi:10.1016/j.vaccine.2010.07.061

25. Assarehzadegan MA, Sankian M, Jabbari F, Tehrani M, Varasteh A. Expression of the recombinant major allergen of Salsola kali pollen (Sal k 1) and comparison with its low-immunoglobulin E-binding mutant. Allergol Int. 2010;59(2):213-222. doi:10.2332/ allergolint.09-OA-0155

26. Gheybi E, Amani J, Salmanian AH, Mashayekhi F, Khodi S. Designing a recombinant chimeric construct contain MUC1 and HER2 extracellular domain for prediagnostic breast cancer. Tumour Biol. 2014;35(11):11489-11497. doi:10.1007/s13277014-2483-y

27. Abrahamson M. Human cysteine proteinase inhibitors. Isolation, physiological importance, inhibitory mechanism, gene structure and relation to hereditary cerebral hemorrhage. Scand J Clin Lab Invest Suppl. 1988;191:21-31.

28. Saitoh E, Sabatini LM, Eddy RL, et al. The human cystatin C gene (CST3) is a member of the cystatin gene family which is localized on chromosome 20. Biochem Biophys Res Commun. 1989;162(3):1324-1331.

29. Filler G, Bokenkamp A, Hofmann W, Le Bricon T, Martinez-Bru C, Grubb A. Cystatin C as a marker of GFR--history, indications, and future research. Clin Biochem. 2005;38(1):1-8. doi:10.1016/j. clinbiochem.2004.09.025

30. Jiang R, Xu C, Zhou X, Wang T, Yao G. Detection of cystatin C biomarker for clinical measurement of renal disease by developed ELISA diagnostic kits. J TransI Med. 2014;12:205. doi:10.1186/1479-5876-12-205

31. Dierkes J, Westphal S, Luley C. Serum homocysteine increases after therapy with fenofibrate or bezafibrate. Lancet. 1999;354(9174):219-220. doi:10.1016/s0140-6736(99)02153-4

32. Cornwall GA, Hsia N. A new subgroup of the family 2 cystatins. Mol Cell Endocrinol. 2003;200(1-2):1-8. doi:10.1016/S03037207(02)00408-2 